\title{
Classroom Furniture Mismatch and Back Pain Among Adolescent School-Children in Abha City, Southwestern Saudi Arabia
}

\author{
Abdullah Assiri ${ }^{1}$, Ahmed A. Mahfouz ${ }^{2,3, *(\mathbb{D}}$, Nabil J. Awadalla ${ }^{2,4}{ }^{\complement}$, Ahmed Y. Abouelyazid $^{2,4} \mathbb{C}^{(}$, \\ Medhat Shalaby ${ }^{1,5}$, Ahmed Abogamal ${ }^{5}{ }^{\circ}$, Abdullah Alsabaani ${ }^{2}{ }^{-}$and Fatima Riaz ${ }^{2}$ \\ 1 Department of Internal Medicine, College of Medicine, King Khalid University, Abha 61421, Saudi Arabia; \\ aassiri@yahoo.com (A.A.); medhatshalaby57@gmail.com (M.S.) \\ 2 Department of Family and Community Medicine, College of Medicine, King Khalid University, Abha 61421, \\ Saudi Arabia; njgirgis@yahoo.co.uk (N.J.A.); drzizous2000@yahoo.com (A.Y.A.); \\ dr.alsabaani@hotmail.com (A.A.); fatima.riaz786@yahoo.com (F.R.) \\ 3 Department of Epidemiology, High Institute of Public Health, Alexandria University, \\ Alexandria 21511, Egypt \\ 4 Department of Community Medicine, College of Medicine Mansoura University, Mansoura 35516, Egypt \\ 5 Department of Rheumatology, Faculty of Medicine, Al Azhar University, Cairo 11651, Egypt; \\ ahmedfathy15@yahoo.com \\ * Correspondence: mahfouz2005@gmail.com; Tel.: +966-17-241-7629; Fax: +966-17-241-7771
}

Received: 7 March 2019; Accepted: 16 April 2019; Published: 18 April 2019

\begin{abstract}
Objective: To explore the potential classroom furniture mismatch with students' anthropometric measurements and back pain related to sitting for extended periods. Methods: This cross-sectional study was carried out on all twelve male and female intermediate and secondary schools located in Abha city. Anthropometric and classroom furniture measurements were assessed, and the mismatch was determined using standardized methods. Students were also screened for back pain related to long sitting at school. Results: A total number of 879 students was selected. The study revealed seat height mismatch in both intermediate, and secondary school of $84.3 \%$, and $75.6 \%$, respectively. Seat depth mismatch was $74.0 \%$ in intermediate schools and reached $84.5 \%$ in secondary schools. The desk height was improper for $94.1 \%$, and $82.3 \%$ of students in intermediate, and secondary schools, respectively. The levels of mismatch differ significantly by grade level and gender. A prevalence of $10.8 \%$ of back pain related to long sitting at school was found. In multivariable logistic regression, males, intermediate school children, and the presence of buttock-popliteal length/seat depth mismatch were significantly associated with pain. On the other hand, practicing exercise was a significant protective factor. Conclusions: There is a prevalent mismatch between students' dimensions and existing schools' furniture. School furniture providers should take in consideration the average Saudi students' dimensions, while designing school furniture especially for males, and at intermediate schools, or provide schools with adjustable seats and desks.
\end{abstract}

Keywords: back pain; school children; classroom furniture; mismatch; ergonomics

\section{Introduction}

School children attend schools for a considerable amount of time, $6 \mathrm{~h}$ a day on average. They spend the largest part of their time at school in performing different related activities, which lead them to be seated on their seats constantly for a long time [1].

Literature review has shown that school children often use furniture that does not match their anthropometric requirements $[2,3]$. This has been recognized by the fact that school furniture dimensions 
are usually based on findings not correlated with the students' requirements [4]. School children are growing and changing in dimensions. This results in high variability in body dimensions in the same school grade. Ergonomic mismatch develops when several subjects of different anthropometric dimensions use a fixed one-size-fits-all furniture [5].

Students are especially predisposed of negative health impacts from inadequately designed and mismatched furniture, due to prolonged periods of sitting. Furthermore, improper school furniture may also be accountable for poor sitting posture. Improper students' posture, while using school furniture, is considered one of the factors that may increase the possibility of developing back pain [6]. Back pain among school children is a highly prevalent problem, which could influence their learning capabilities [2] and substantially impact their adolescent and adulthood quality of life [7]. The reasons for the development of back pain remains debatable, and mainly relates to musculoskeletal strain associated with bad ergonomics during daily activities [8,9]. The use of ergonomically matched school furniture may reduce children's fatigue and back pain in the school environment [10].

Ergonomic data regarding school furniture in Abha city, south western Saudi Arabia, are scarce. Also, there is a lack in literature regarding back pain related to long periods of sitting at school and its relationship with school furniture mismatch. The objectives of the present study were to investigate whether the current school furniture, which were provided by school authorities, match with anthropometric data of adolescent children and to explore the relation with back pain related to long sitting.

\section{Methods}

\subsection{Study Design}

The study design was a cross-sectional study.

\subsection{Study Settings}

The study was conducted on all twelve male and female intermediate and secondary schools located in Abha city, Asser Region, Southwestern Saudi Arabia. The age of the intermediate and secondary grades students in Saudi Arabia range from 13-15 years, and 16-18 years, respectively.

One class was randomly chosen from each of the three levels in each school. Consent letters were sent to the guardians of all children in each of the selected classes. During the field visit, all present children with approval from their parents were examined. All procedures performed in studies involving human participants were in accordance with the ethical standards of the institutional and/or national research committee and with the 1964 Helsinki Declaration and its later amendments or comparable ethical standards. The research proposal was revised and accepted by the ethical committee of King Khalid University (REC \# 2014-03-09). Approval was also obtained from school authorities.

\subsection{Anthropometric Measurements}

Student measurements (except height) were assessed while setting erect on a flat horizontal surface, with knees bent $90^{\circ}$, and without shoes. Height was measured while standing erect without shoes. The following body dimensions were assessed [5,11,12]:

- Elbow height. The distance from the student's seated surface to his olecranon (bottom of the elbow tip) was measured while flexing the elbow at $90^{\circ}$.

- Knee height. The vertical distance from the foot resting surface to the top of the knee cap just in back and above the patella was measured with the knee flexed at $90^{\circ}$.

- Popliteal height. The vertical distance from the posterior surface of the knee or popliteal space to the foot resting surface was measured with the knee flexed at $90^{\circ}$.

- Buttock-popliteal length. The horizontal distance from the posterior surface of the knee or popliteal space to the posterior surface of the buttock was measured with the knee flexed at $90^{\circ}$. 
- Height. While the student stands upright, looking straight forward, the vertical distance from the floor to the top of the head was measured.

- Children's weight was measured in $\mathrm{kg}$, using standard methods, while the child wearing minimal clothes.

\subsection{Classroom Furniture Dimensions' Measurements}

For each school, their classrooms' desk/seat furniture were inspected, and their dimensions were measured. The following classroom furniture measurements were assessed to be used for calculating student's furniture mismatch $[5,11,12]$ :

- Seat height is the vertical distance from the highest point on the front of the seat to the floor.

- Seat depth. The chair seat depth is the horizontal distance of the sitting surface from the back of the seat, at a point where it is assumed that the buttocks begins, to the front of the seat.

- Desk/table height. The desk/table height is the vertical distance from the floor to the top of the front edge of the desk or table.

Assessment of ergonomic mismatch [5,11,12]:

- Popliteal Height and Seat Height Mismatch. Popliteal and seat height as any seat height that was either $>95 \%$ or $<88 \%$ of the popliteal height.

- Buttock-Popliteal Length and Seat Depth Mismatch. A mismatch of buttock-popliteal length to seat depth was defined as a seat that is either $<80 \%$ or $>95 \%$ of the buttock-popliteal length.

- Knee Height and Desk/Table Height Mismatch. Desk-knee clearance should exceed $2 \mathrm{~cm}$. Thus, a mismatch is defined to occur when a desk/table is $<2 \mathrm{~cm}$ higher than the knee height.

- Elbow Rest Height and Desk/Table Height Mismatch. Mismatching was considered when the following matching equation was not fulfilled: Elbow height $\leq$ Desk height $\leq$ Elbow height $+5 \mathrm{~cm}$

Intensive training was performed for the data collectors to standardize methods of measurements and to minimize inter and intra observer variations.

\subsection{Back Pain}

Students were screened for back pain related to long sitting at school. The daily schedule for students is usually 6 classes per day. Each class lasts for $50 \mathrm{~min}$. Students are usually sitting all the time of the class. Only five minutes break were allowed between classes. During the day there is a single break for $15 \mathrm{~min}$.

Back pain was assessed using the following question: "During the past three months have you felt any pain or ache in the back area while sitting for a long time at school, which has lasted for one day or longer?" The response alternatives were "yes", "no" or "I don't know". The last option was regarded as "no". Screening for back pain related to long sitting at school was selected because it would be a proxy for the health effect of school furniture mismatch, if any.

\subsection{Data Analysis}

Data entry and analysis was done using SPSS program version 22 (IBM Corporation, Armonk, NY, USA). The student's $t$-test was used to compare anthropometric measurements between boys and girls in intermediate and secondary schools. Also, chi-square test was used to evaluate the association between gender and levels of mismatch. P value of less than $5 \%$ was used as level of significance. Proportions with 95\% confidence intervals (95\% CI) were used to present the prevalence of back pain. Multivariable binary logistic regression analysis was used to identify the independent factors associated with back pain related to long sitting at school. Adjusted odds ratios (aOR) and 95\% confidence intervals were calculated. Variables included in the model were, gender, school grade, physical exercise (any regular engagement in physical activities like running, cycling, swimming, brisk walking, playing football, etc.), over weight and obesity, and classroom furniture mismatches. 


\section{Results}

Twelve boys' and girls' schools were included in the current study; six intermediate and six secondary schools in Abha City. The study included 879 students (439 intermediate grade students and 440 secondary grade students). The mean and standard deviation values of the student's anthropometric measurements by grade and gender were presented in Table 1 . The table shows that the average body mass index (BMI) values were significantly higher $(p=0.01)$ among boys $\left(23.87 \pm 6.48 \mathrm{~kg} / \mathrm{m}^{2}\right)$ compared to girls $\left(22.24 \pm 4.27 \mathrm{~kg} / \mathrm{m}^{2}\right)$ in the secondary grade. On the other hand, the BMI values were not significantly different among boys and girls in the intermediate grade.

Regarding other anthropometric measurement, the table shows that popliteal height in intermediate grade was significantly $(p=0.001)$ higher among boys $(43.10 \pm 2.50 \mathrm{~cm})$ compared to girls $(41.40 \pm 2.46 \mathrm{~cm})$. A similar trend was observed in intermediate and secondary grades where average boys' popliteal height (in $\mathrm{cm}$ ), buttock popliteal length (in $\mathrm{cm}$ ) and knee-height (in $\mathrm{cm}$ ) were significantly higher compared to girls. Similarly, in secondary grade, the average values for elbow height (in cm) among boys was significantly higher compared to girls. Meanwhile, no significant difference was observed in intermediate grade.

Table 2 shows ergonomic assessment of student's furniture match/mismatch percentage by gender and grade level. Overall, most of the students in intermediate and secondary schools showed mismatch in the three studied measurements (Popliteal Height/seat height, Buttock-popliteal length/seat depth and elbow rest height/desk height). The overall seat height mismatch in both intermediate and secondary school reached $84.3 \%$, and $75.6 \%$, respectively. The seat depth mismatch was $74.0 \%$ in intermediate schools and reached $84.5 \%$ in secondary schools. The desk height was improper for $94.1 \%$ and $82.3 \%$ of students in intermediate and secondary schools respectively. The majority of mismatch in seat and desk heights showed a high mismatch (too high seat and desk). On the other hand, most of mismatch in seat depth was low mismatch indicating a shallow seat (data not tabulated). It was found that none of the students experienced knee clearance problem as the knee-desk distance exceeded $2 \mathrm{~cm}$ height for all the students in both grades.

Regarding gender differences, Table 2 shows that there were significant differences in the percent of mismatch, where males had a higher buttock popliteal length/seat depth in intermediate and secondary, and popliteal height in secondary schools only. On the other hand, the table shows a significant difference where females had higher values in knee height/desk height in intermediate and secondary grades.

The study showed that 95 students complained of back pain related to long sitting at school giving a prevalence of $10.8 \%$ (95\% CI: $9.2 \%-12.3 \%)$.

Table 3 shows factors associated with back pain related to long sitting at school. Males were significantly having back pain compared to females (aOR $=2.101,95 \% \mathrm{CI}: 1.218-3.625)$. Similarly, intermediate school children were significantly having more back pain (aOR =2.242, 95\% CI: 1.364-3.685) compared to secondary school students. The only significant mismatch measurement associated with back pain was buttock-popliteal length / seat depth (aOR =3.386, 95\% CI: 1.403-8.173). On the other hand, the study showed that undertaking exercise was a significant protective factor for back pain $(\mathrm{aOR}=0.640,95 \% \mathrm{CI}: 0.405-0.901)$. 
Table 1. Anthropometric measurements of students participated in the study $(n=879)$.

\begin{tabular}{|c|c|c|c|c|c|c|c|c|}
\hline \multirow{2}{*}{$\begin{array}{l}\text { Anthropometric } \\
\text { Measurements }\end{array}$} & \multicolumn{4}{|c|}{ Intermediate } & \multicolumn{4}{|c|}{ Secondary } \\
\hline & $\begin{array}{l}\text { All }(n=439) \\
\text { Mean (SD) }\end{array}$ & $\begin{array}{c}\text { Boys }(n=145) \\
\text { Mean }(S D)\end{array}$ & $\begin{array}{l}\text { Girls }(n=294) \\
\text { Mean (SD) }\end{array}$ & $p$-Value & $\begin{array}{l}\text { All }(n=440) \\
\text { Mean (SD) }\end{array}$ & $\begin{array}{c}\text { Boys }(n=329) \\
\text { Mean }(S D)\end{array}$ & $\begin{array}{l}\text { Girls }(n=111) \\
\text { Mean (SD) }\end{array}$ & $p$-Value \\
\hline Weight (Kg) & $54.47(16.13)$ & $58.97(19.10)$ & $52.24(13.95)$ & 0.001 & $64.02(18.68)$ & $67.25(19.37)$ & $54.75(12.60)$ & 0.001 \\
\hline Height $(\mathrm{cm})$ & $157.31(8.95)$ & $163.13(10.51)$ & $154.44(6.36)$ & 0.001 & $164.77(9.30)$ & $167.62(8.02)$ & $156.46(7.67)$ & 0.001 \\
\hline Body Mass Index $\left(\mathrm{kg} / \mathrm{m}^{2}\right)$ & $21.82(5.42)$ & $21.86(5.85)$ & $21.80(5.21)$ & 0.91 & $23.45(6.03)$ & $23.87(6.48)$ & $22.24(4.27)$ & 0.01 \\
\hline Popliteal Height $(\mathrm{cm})$ & $41.97(2.60)$ & $43.10(2.50)$ & $41.40(2.46)$ & 0.001 & $43.67(7.08)$ & $45.17(6.12)$ & $41.17(2.55)$ & 0.001 \\
\hline Buttock-Popliteal Length $(\mathrm{cm})$ & $52.37(5.21)$ & $56.86(4.75)$ & $50.15(3.81)$ & 0.001 & $54.72(6.39)$ & $56.64(5.07)$ & $50.08(3.36)$ & 0.001 \\
\hline Knee-Height $(\mathrm{cm})$ & $49.00(4.43)$ & $51.48(3.66)$ & $48.01(2.60)$ & 0.001 & $51.70(5.69)$ & $53.23(3.67)$ & $48.31(2.90)$ & 0.001 \\
\hline Elbow Height (cm) & $61.32(4.52)$ & $61.58(4.86)$ & $61.33(3.65)$ & 0.54 & $64.80(5.05)$ & $66.09(3.53)$ & $61.48(4.17)$ & 0.001 \\
\hline
\end{tabular}

$p$-Values: comparing boys and girls.

Table 2. Students- furniture match/mismatch percentages by gender and grade level $(n=879)$.

\begin{tabular}{|c|c|c|c|c|c|c|}
\hline \multirow{3}{*}{ Grade/Gender } & \multicolumn{6}{|c|}{ Ergonomic Assessment } \\
\hline & \multicolumn{2}{|c|}{ Popliteal Height/Seat Height } & \multicolumn{2}{|c|}{ Buttock-Popliteal Length/Seat Depth } & \multicolumn{2}{|c|}{ Elbow Rest Height/Desk Heigh } \\
\hline & $\begin{array}{l}\text { Match } \\
\text { No. (\%) }\end{array}$ & $\begin{array}{l}\text { Mismatch } \\
\text { No. (\%) }\end{array}$ & $\begin{array}{l}\text { Match } \\
\text { No. (\%) }\end{array}$ & $\begin{array}{l}\text { Mismatch } \\
\text { No. (\%) }\end{array}$ & $\begin{array}{l}\text { Match } \\
\text { No. (\%) }\end{array}$ & $\begin{array}{l}\text { Mismatch } \\
\text { No. }(\%)\end{array}$ \\
\hline \multicolumn{7}{|l|}{ Intermediate } \\
\hline Boys $(n=145)$ & $22(15.2)$ & $123(84.8)$ & $9(6.2)$ & $136(93.8)$ & $20(13.8)$ & $125(86.2)$ \\
\hline Girls $(n=294)$ & $47(16.0)$ & $247(84.0)$ & $105(35.7)$ & $189(64.3)$ & $6(2.0)$ & $288(98.0)$ \\
\hline Total $(n=439)$ & $69(15.7)$ & $370(84.3)$ & $114(26.0)$ & $325(74.0)$ & $26(5.9)$ & $412(94.1)$ \\
\hline$p$-value & \multicolumn{2}{|c|}{0.890} & \multicolumn{2}{|c|}{0.001} & \multicolumn{2}{|c|}{0.001} \\
\hline \multicolumn{7}{|l|}{ Secondary } \\
\hline Boys $(n=329)$ & $63(19.2)$ & $266(80.8)$ & $28(8.5)$ & $301(91.5)$ & $68(20.7)$ & $261(79.3)$ \\
\hline Girls $(n=111)$ & $44(39.6)$ & $67(60.4)$ & $40(36.0)$ & $71(64.0)$ & $3(2.7)$ & $108(97.3)$ \\
\hline Total $(n=440)$ & $107(24.4)$ & $333(75.6)$ & $68(15.5)$ & $372(84.5)$ & $71(16.1)$ & $369(83.9)$ \\
\hline$p$-value & \multicolumn{2}{|c|}{0.001} & \multicolumn{2}{|c|}{0.001} & \multicolumn{2}{|c|}{0.001} \\
\hline
\end{tabular}


Table 3. Personal and school furniture mismatch factors associated with back pain related to long sitting at school among the study sample of adolescents $(n=876)$.

\begin{tabular}{|c|c|c|}
\hline \multicolumn{2}{|l|}{ Factors } & aOR $(95 \% \mathrm{CI})$ \\
\hline \multirow{2}{*}{ Gender } & Female & Ref \\
\hline & Male & $2.101(1.218-3.625)$ \\
\hline \multirow{2}{*}{ Undertaking exercise } & No & Ref \\
\hline & yes & $0.64(0.405-0.901)$ \\
\hline \multirow{2}{*}{ School grade } & Secondary & Ref \\
\hline & Intermediate & $2.242(1.364-3.685)$ \\
\hline \multirow{2}{*}{$\operatorname{BMI}\left(\mathrm{kg} / \mathrm{m}^{2}\right)$} & $18.5-24.9$ & Ref \\
\hline & 25 and more & $0.766(0.457-1.283)$ \\
\hline \multirow{2}{*}{ Popliteal Height/Seat Height mismatch } & No & Ref \\
\hline & yes & $0.782(0.453-1.350)$ \\
\hline \multirow{2}{*}{ Buttock-popliteal length/Seat Depth mismatch } & No & Ref \\
\hline & yes & $3.386(1.403-8.173)$ \\
\hline \multirow{2}{*}{ Elbow rest height/Desk Height mismatch } & No & Ref \\
\hline & yes & $0.753(0.389-1.456)$ \\
\hline
\end{tabular}

aOR: adjusted odds ratios.

\section{Discussion}

Overall, the majority of students in intermediate and secondary schools showed mismatch in the three studied measurements (Popliteal Height/seat height, Buttock-popliteal length/seat depth and knee height/desk height). These results were in accordance with Iranian study [12], which reported considerable mismatch between body dimensions of the school students and the classroom furniture. Also, another Indonesian study reported a classroom furniture standards/student's dimensions mismatch values ranging from $63.4 \%$ to $96.7 \%$ [13]. Similar results were observed in Chilean elementary schools [3] and Michigan schools [5]. The high mismatch percentage in the present study between furniture and students' anthropometry could be explained by the fact that the purchasing of the furniture was made without taking in consideration the ergonomic principles and the variability of students' dimensions within the same grade level and across the different grades. These conditions may increase the risk of back pain and spinal problems [12].

Interestingly, the current study observed that the majority of mismatch in seat and desk heights were high mismatch. On the other hand, most of mismatch in seat depth was low mismatch. This indicates that most of the students are using too high and too narrow chairs. The same results were reported in Iranian study [14].

On examining the relation between students' grade and schoolroom furniture mismatch, the present study detected that mismatch significantly decreased with increased grade level for seat height and disk height while significantly increased for seat depth. This could be explained by the fact that high mismatch (high desk) decrease with students' growth. On the other hand, the low mismatch in seat depth (narrow chair) increase with students' growth. The same findings were observed in the Iranian study [12].

Regarding gender differences, the present study observed that boys had a higher seat depth mismatch (narrow seat) in intermediate and secondary, and seat height mismatch (high seat) in secondary schools only compared to girls. On the other hand, the girls had higher mismatch values of desk height in intermediate and secondary grades compared to boys (high desk). The gender difference in mismatch was observed in other previous studies $[5,10,12,13,15]$. The effect of gender on frequency of mismatch could be attributed to the developmental differences at the time of puberty between boys and girls at each grades [5]. 
The current study revealed that $10.8 \%$ of school children were suffering back pain related to long sitting at school. The back pain related to prolonged sitting may be due to sitting with improper posture or using school furniture that mismatching the anthropometric measurements of school children $[9,16]$. Back muscles strain resulted from exertions used to maintain balance and comfort while sitting on improperly designed school chairs is a causal factor for back pain at schools [6,10]. Furthermore, the instability resulted from mismatched school furniture forced the students to take improper postures while sitting, which consequently exaggerating the back-pain problem $[5,9,15]$. The result of the present study endorses these findings as the buttock-popliteal length/seat depth mismatch was an independent factor associated with long sitting back pain at school. the use of wider seat depth than buttock-popliteal length of the student may interfere with the use of the backrest of the seat and increase the pressure on students' thighs [14,17]. Also, the use of narrow chairs may interfere with thigh support during sitting causing instability and discomfort [18]. Another independent factor for back pain in the present study was being in intermediate school grade. This could be explained by the fast-growing body dimensions during this age period and the subsequent highly prevalent desk/chair mismatches.

The present study revealed that the risk of back pain related to sitting was higher among male students compared with females. Posture during sitting differs significantly by gender. Females tend to take more comfortable posture with back rest compared with males. This posture places males at a greater risk of developing back pain and disc herniation [19-21].

The current study endorses the protective effect of practicing exercise in minimizing back pain related to long sitting at school. This is in agreement with previous studies [22-24]. The possible explanation of this beneficial effect is that regular exercises increase intercostal and back muscles strength and consequently decrease frequency and intensity of back pain [25].

\section{Limitations}

The outcomes of the current study should be considered in light of some study limitations. The first limitation was that the samples were taken from one city in southwestern region of Saudi Arabia. Therefore, it is possible that the selected schools in the Abha city are not representative of other areas of the Saudi Arabia. Around $97.8 \%$ of the study samples were Saudis. Taking other nationalities into consideration is likely to provide small numbers. Therefore, the effect of students' nationality was not considered during analysis. Anthropometric dimensions of the school children could be affected by student' nationality. Another study limitation was a lack of assessment of the students' posture during sitting.

\section{Conclusions}

There is a considerable mismatch between the body dimensions of the students and the existing classroom furniture. Most of the mismatch was a high mismatch for seat and desk heights and low mismatch for seat depth. This indicated that most of the students in the intermediate and secondary schools in Abha, southwestern Saudi Arabia, are sitting on too high, on too narrow chairs, and improper desk height. The levels of mismatch differ by students' grade level and gender. These possibly resulted from different growth rates and furniture measurements. Back pain related to long sitting at school is evident. The risk is higher among males, at intermediate schools and in the presence of improper chairs dimensions. Practicing physical exercise has a beneficial effect in minimizing back pain. The findings of the study suggest that, the manufacturers should take into consideration the Saudi students' dimensions, while designing school furniture. It is recommended that a nation-wide study should be established to assess the diversity of mismatch in terms of percentiles to help designers. Another suggestion is to provide schools with adjustable seats and desks. Some studies recommended adjustable school furniture to improve students' posture, learning capabilities, and reduce the risk of musculoskeletal complaints [26-28]. It is also highly recommended to encourage practicing physical exercises among school children. 
Author Contributions: Funding acquisition and project supervision, A.A. (Abdullah Assiri); Conceptualization, A.A. (Abdullah Assiri), A.A.M., N.J.A., M.S.; Methodology, M.S., N.J.A., A.Y.A.; formal analysis, A.A.M., A.Y.A., N.J.A.; investigation, A.A. (Abdullah Alsabaani), M.S., A.A. (Ahmed Abogamal), F.R.; original draft preparation, A.A.M., N.J.A., review and editing, A.A. (Abdullah Assiri), A.A.M., N.J.A.

Funding: The research was supported by a grant provided by King Abdel Aziz City for Science and Technology (34-444), Saudi Arabia.

Acknowledgments: The authors would like to thank the school authorities, teachers, and students' parents who gave us permission to do the anthropometric measurement of their children. The authors also thank the female health care workers from King Khalid University who participated in the data collection of the female students.

Conflicts of Interest: The authors certify that there is no conflict of interest with any financial organization regarding the material discussed in the manuscript.

\section{References}

1. Agha, S.R. School furniture match to students' anthropometry in the Gaza Strip. Ergonomics 2010, 53, $344-354$. [CrossRef]

2. Savanur, C.; Altekar, C.; De, A. Lack of conformity between Indian classroom furniture and student dimensions: Proposed future seat/table dimensions. Ergonomics 2007, 50, 1612-1625. [CrossRef]

3. Castellucci, H.; Arezes, P.; Viviani, C. Mismatch between classroom furniture and anthropometric measures in Chilean schools. Appl. Ergon. 2010, 41, 563-568. [CrossRef]

4. Corlett, E. Background to sitting at work: Research-based requirements for the design of work seats. Ergonomics 2006, 49, 1538-1546. [CrossRef]

5. Parcells, C.; Stommel, M.; Hubbard, R.P. Mismatch of classroom furniture and student body dimensions: Empirical findings and health implications. J. Adolesc. Health 1999, 24, 265-273. [CrossRef]

6. Trevelyan, F.C.; Legg, S.J. Risk factors associated with back pain in New Zealand school children. Ergonomics 2011, 54, 257-262. [CrossRef] [PubMed]

7. Meziat Filho, N.; Coutinho, E.S.; e Silva, G.A. Association between home posture habits and low back pain in high school adolescents. Eur. Spine J. 2015, 24, 425-433. [CrossRef]

8. Kovacs, F.M.; Gestoso, M.; del Real, M.T.G.; López, J.; Mufraggi, N.; Méndez, J.I. Risk factors for non-specific low back pain in schoolchildren and their parents: A population based study. Pain 2003, 103, 259-268. [CrossRef]

9. Noll, M.; Candotti, C.T.; Rosa, B.N.d.; Loss, J.F. Back pain prevalence and associated factors in children and adolescents: An epidemiological population study. Revista de Saude Publica 2016, 50, 31. [CrossRef] [PubMed]

10. Brewer, J.; Davis, K.; Dunning, K.; Succop, P. Does ergonomic mismatch at school impact pain in school children? Work 2009, 34, 455-464.

11. Skoffer, B. Low back pain in 15-to 16-year-old children in relation to school furniture and carrying of the school bag. Spine 2007, 32, E713-E717. [CrossRef]

12. Dianat, I.; Karimi, M.A.; Hashemi, A.A.; Bahrampour, S. Classroom furniture and anthropometric characteristics of Iranian high school students: Proposed dimensions based on anthropometric data. Appl. Ergon. 2013, 44, 101-108. [CrossRef]

13. Lu, C.-W.; Lu, J.-M. Evaluation of the Indonesian National Standard for elementary school furniture based on children's anthropometry. Appl. Ergon. 2017, 62, 168-181.

14. Dianat, I.; Javadivala, Z.; Asghari-Jafarabadi, M.; Asl Hashemi, A.; Haslegrave, C.M. The use of schoolbags and musculoskeletal symptoms among primary school children: Are the recommended weight limits adequate? Ergonomics 2013, 56, 79-89. [CrossRef] [PubMed]

15. Musa, A.; Ismaila, S.; Adejuyigbe, S.; Akinyemi, O. Ergo-effects of designed school furniture and sitting positions on students' behaviour and musculo-skeletal disorder in Nigerian tertiary institutions. Manag. Sci. Lett. 2011, 1, 331-334. [CrossRef]

16. Zhang, L.; Helander, M.G.; Drury, C.G. Identifying factors of comfort and discomfort in sitting. Hum. Factors 1996, 38, 377-389. [CrossRef]

17. Milanese, S.; Grimmer, K. School furniture and the user population: An anthropometric perspective. Ergonomics 2004, 47, 416-426. [CrossRef] [PubMed]

18. Gouvali, M.; Boudolos, K. Match between school furniture dimensions and children's anthropometry. Appl. Ergon. 2006, 37, 765-773. [CrossRef] 
19. Wilder, D.; Pope, M. Epidemiological and aetiological aspects of low back pain in vibration environments-An update. Clin. Biomech. 1996, 11, 61-73. [CrossRef]

20. Wilder, D.G.; Pope, M.H.; Frymoyer, J.W. The biomechanics of lumbar disc herniation and the effect of overload and instability. J. Spinal Disord. 1988, 1, 16-32. [CrossRef] [PubMed]

21. Dunk, N.M.; Callaghan, J.P. Gender-based differences in postural responses to seated exposures. Clin. Biomech. 2005, 20, 1101-1110. [CrossRef]

22. Skoffer, B.; Foldspang, A. Physical activity and low-back pain in schoolchildren. Eur. Spine J. 2008, 17, 373-379. [CrossRef]

23. Wedderkopp, N.; Kjær, P.; Hestbæk, L.; Korsholm, L.; Leboeuf-Yde, C. High-level physical activity in childhood seems to protect against low back pain in early adolescence. Spine J. 2009, 9, 134-141. [CrossRef]

24. Scarabottolo, C.C.; Pinto, R.; Oliveira, C.; Zanuto, E.; Cardoso, J.; Christofaro, D. Back and neck pain prevalence and their association with physical inactivity domains in adolescents. Eur. Spine J. 2017, 26, 2274-2280. [CrossRef]

25. Salminen, J.J.; Maki, P.; Oksanen, A.; Pentti, J. Spinal mobility and trunk muscle strength in 15-year-old schoolchildren with and without low-back pain. Spine 1992, 17, 405-411. [CrossRef]

26. Kroemer, K.H. Fitting the Human: Introduction to Ergonomics/Human Factors Engineering; CRC Press: Boca Raton, FL, USA, 2017.

27. Jung, H.S. A prototype of an adjustable table and an adjustable chair for schools. Int. J. Ind. Ergon. 2005, 35, 955-969. [CrossRef]

28. Castellucci, H.; Arezes, P.; Molenbroek, J.; De Bruin, R.; Viviani, C. The influence of school furniture on students' performance and physical responses: Results of a systematic review. Ergonomics 2017, 60, 93-110. [CrossRef]

(C) 2019 by the authors. Licensee MDPI, Basel, Switzerland. This article is an open access article distributed under the terms and conditions of the Creative Commons Attribution (CC BY) license (http://creativecommons.org/licenses/by/4.0/). 